\section{European Medical Research Group (Meeting held on 5 February 1991)}

The European Medical Research Group met at the Medical Society of London, Lettsom House, on 5 February 1991. The guest speaker was Dr A.M. Heagerty, Department of Medicine, University of Leicester, who gave a lecture on 'Does hypertension actually cause vascular growth?'.

Following a period of questions and discussion, a poster session was held demonstrating the research in progress of some members of the Group. Their abstracts are published below.

Gastric metaplasia in the distal duodenum and chronic NSAID usage

J.D. Arnold, G.T. Williams, F.N. Khan, G. Swift, J.S. Morris and J. Rhodes

Department of Gastroenterology and Pathology, University Hospital of Wales, Cardiff, UK.

Mucosal ulceration associated with non-steroidal antiinflammatory drugs (NSAID) may extend to the second

\section{Protein binding of certain drugs in cancer}

R. Raveendran, W. Heybroek, M. Caulfield, S.M.L. Abrams, M. Lawson, P. Turner, P.F.M. Wrigley and M. Slevin

Departments of Clinical Pharmacology and Medical Oncology, St Bartholomew's Hospital, West Smithfield, London EC1A $7 B E, U K$.

The study was to investigate the concentration of serum proteins and in vitro protein binding of indomethacin, morphine and methotrexate in cancer patients. Twenty patients with different types of cancer and 20 normal subjects participated in the study. The patient group was subdivided into patients with 'active disease' and those 'in remission'. Serum albumin and alpha-1 acid glycoprotein were estimated. The protein binding of drugs was determined using equilibrium dialysis. Results were analysed using a two tailed Student's $t$ test. part of the duodenum and may be associated with gastric metaplasia and Helicobacter pylori (H. pylori) colonization. We have examined biopsies from the second part of the duodenum in patients receiving long term NSAIDs compared with normal volunteers. Multiple biopsies were taken from 8 patients on NSAIDs ( 5 female, mean age 53 years) and 8 healthy volunteers ( 5 female, mean age 44 years). Indomethacin $(n=5)$ and diclofenac $(n=3)$ were the drugs involved. The biopsies were stained by haematoxylin and eosin and assessed by a histopathologist who was unaware of the treatment. The following parameters were recorded: (a) acute and chronic inflammation, (b) vascular ectasia, (c) oedema, (d) villous height, (e) gastric metaplasia. Giemsa stained biopsies were examined for $H$. pylori. Histological abnormalites of mild degree were found in patients in the NSAID group and consisted of oedema of lamina propria $(n=4)$, vascular ectasia $(n=4)$ and minimal villous atrophy $(n=3)$. None of the subjects had evidence of gastric metaplasia or $\boldsymbol{H}$. pylori infection. Although chronic NSAID ingestion is associated with mild oedema and vascular ectasia it does not appear to cause significant inflammatory cell infiltration or gastric metaplasia in the distal duodenum in man.

\title{
Conclusions
}

Alpha-1 acid glycoprotein levels were increased in cancer but less so in remission. Albumin levels were reduced in active disease but remained normal in remission. Alpha-1 acid glycoprotein levels negatively correlated with albumin in patients $(r=-0.73, P<0.02)$ but a poor positive correlation $(r=0.15)$ was found in normals. The protein binding of methotrexate was reduced in active disease but the binding of indomethacin and morphine did not differ in cancer.

\begin{tabular}{|c|c|c|c|c|c|}
\hline \multirow[b]{2}{*}{ Subjects } & \multicolumn{2}{|c|}{ Protein concentration } & \multicolumn{3}{|c|}{ Protein binding } \\
\hline & $\begin{array}{c}\text { Albumin } \\
(\mathrm{g} / \mathrm{l})\end{array}$ & $\begin{array}{c}\text { Alpha-1 AGP } \\
(m g / l)\end{array}$ & Indomethacin & $\begin{array}{l}\text { (\% bound) } \\
\text { Morphine }\end{array}$ & Methotrexate \\
\hline Control & $58.94 \pm 9.9$ & $687 \pm 130$ & $97 \pm 0.47$ & $33 \pm 3.97$ & $39 \pm 4.68$ \\
\hline Patients & $54.77 \pm 19.9$ & $1367 \pm 856^{*}$ & $97 \pm 0.79$ & $31 \pm 4.65$ & $37 \pm 6.41$ \\
\hline $\begin{array}{l}\text { Active } \\
\text { disease }\end{array}$ & $47.67 \pm 15.91^{*}$ & $1802 \pm 1025^{*}$ & $96 \pm 0.93$ & $29 \pm 4.94$ & $34 \pm 7.12^{*}$ \\
\hline Remission & $61.86 \pm 6.62$ & $931 \pm 273^{*}$ & $97 \pm 0.55$ & $33 \pm 3.89$ & $40 \pm 4.04$ \\
\hline
\end{tabular}

Values are mean \pm s.d. ${ }^{*} P<0.05$ when compared to control value. 